\section{MELHORAMENTOS EM APARELHO ELETROEJACULADOR PARA COBAIAS (CAVIA PORCELLUS)}

\author{
ORLANDO REBELO DOS SANTOS \\ Técnico Nivel Superior \\ Instituto de Pesquisas Energéticas e Nucleares
}

RENATO CAMPANARUT BARNABE

Professor Adjunto

Faculdade de Medicina Veterinária

e Zootecnia da USP

VALQUIRIA HYPPÓLITO BARNABE

Professor Livre-Docente

Faculdade de Medicina Veterinária

e Zootecnia da USP

MARGO VÂNIA HEHL REBELO DOS SANTOS

Técnico Nível Superior

Instituto de Pesquisas Energéticas e Nucleares

ALFREDO SGAMBATTI JUNIOR

Técnico Nivel Médio

Instituto de Pesquisas Energéticas e Nucleares

SANTOS, O.R.; BARNABE, R.C.: BARNABI; V.H.: SANTOS, M.V.H.R.; SGAMBATII JÉNIOR, A. Milloramintor $\mathrm{sm}$ aparelho t:letroejaculador para coblias (Cavia porcellus).

Rev.Fae.Med .vet.Zootec.Univ.S.Paulo, 19(1): 75-85, 198 ?

RESUMO: Demonstrou-se método de eletroejaculação $\mathrm{em}$.cobaias por meio de processo efícientc, nāo traumático e de repetição, que se mostrou útil para estudos de efeitos de radiações ou drogas sobre a produção espermática. Fundamentalmente, o aparelho eletroejaculador consiste de quatro circuitos distintos, acoplados entre si, constituídos de fontes de alimentação, circuitos oscilador e estágio de saída, temporizador e circuito de medição, ligado à rede elétrica em $110 \mathrm{~V}-60 \mathrm{~Hz}$. Associando uma carga ativa a saída do aparello, foi fixada a intensidade da corrente em $28 \mathrm{~mA}$. Para a transferência do sinal elćtrico ao animal, foram utilizados 2 eletrodos, um anal e outro lombar, este posicionado entre as vértebras lombares L2 - L3, cuja região foi depilada para receber uma fina camada de pasta para cletrodo, com o intuito de melhorar a transmissão dos impulsos elétricos. Estes, em número máximo de 5 , foram aplicados em intervalos de 10 segundos e duração de 4 segundos. Ao cessar o primeiro estímulo, o pênis foi manipulado suavemente por meio de movimento de distensão conjugado com leve pressão na glande. Durante as colheitas semanais o aparelho funcionou $\mathrm{cm} \mathrm{AC} \mathrm{(onda} \mathrm{quadrada)} \mathrm{com}$ ajuste de tempo de liberação do choque em 4 segundos e frequência em $1000 \mathrm{~Hz}$. De 53 animais foram obtidas 591 ejaculações, ao longo de 16 semanas, recebendo-se o volume ejaculado em coletor contendo $2 \mathrm{ml}$ de tampão tosfato Sorensen e $2 \mathrm{mg}$ de alfa-quimotripsina.

UNITERMOS: Elctroejaculador bipolar*; Cobaias*

\section{INTRODUÇÃO}

Para a obtenção de sêmen de algumas espécies de pequenos animais - camundongos, ratos e covaias - comumente utilizados em experimentos de laboratório, não há possibilidade do uso do método da vagina artificial para colheita do material. Devido a esse fato, o método preconizado é o da eletroejaculação que pode ser aplicado em intervalos regulares, com alta eficiência e repetição, sem provocar danos físicos ao animal. A literatura mostra um número regular de trabalhos com a utilização do método em ratos e camundongos, contudo os parâmetros relatados - número de estímulos elétricos, corrente, tensão, frequência elétrica tipo de onda e de corrente $(\mathrm{AC}, \mathrm{DC})$ - são muito variáveis.

$\mathrm{Na}$ cobaia, a primeira técnica de eletroejaculação 2 foi descrita em 1922 e modificada 13 em 1930. Seguindo os princípios estabelecidos, eram utilizados 3 choques de 5 a 35 volts e 60 ciclos de corrente alternada (AC) durante 10 segundos, por meio de um eletrodo duro na boca do animal e outro, do tipo agulha, na base do crânio 5,14 . A ejaculação era usualmente acompanhada de respostas violentas e espasmódicas de todo o corpo, além de outros inconvenientes como falhas na obtenção do sêmen, necessidade de muitas repetições dos estímulos, coagulação total do material, paradas respiratórias, contração tônica maciça e eversão da mucosa anal.

$\mathrm{Na}$ tentativa de desenvolver um processo menos traumatizante, foram experimentados eletrodos colocados na cabeça e no ânus ou na região lombar 10 . Observando-se mortes de animais devidas a choques na cabeça, o uso de eletrodos nas regióes ano-lombar passou a ser preconizado. A seguir, verificou-se que a utilização de 1000 ciclos $\mathrm{AC}$ aboliam os efeitos colaterais e que o estímulo por meio da onda quadrada produzia resposta ejaculatória mais uniforme 4

Foi descrito 6 um aparelho capaz de fornecer uma onda quadrada intermitente com 1000 ciclos para 0 a 25 volts rms, com automático de três segundos de período de aber. tura e 12 segundos de período de fechamento, sendo utilizados 24 volts rms na maioria das vezes.

Foi também descrito ${ }^{7}$ um aparelho com fonte de sinal, amplificador de 12 watts, voltímetro de 0 a 25 volts e amperímetro para 0 a $25 \mathrm{~mA}$, cuja fonte produzia uma onda quadrada de 1000 ciclos e 12 volts com saída para o amplificador. 0 eletrodo anal com $8 \mathrm{~cm}$ de comprimento $\mathrm{e}$ diâmetro de $0,4 \mathrm{~cm}$ era confeccionado de latão, demonstrando-se ainda a superioridade da posição $\mathrm{L} 2-\mathrm{L} 3$ para a eficiência do eletrodo lombar.

Estudos também foram feitos sobre a utilização do eletrodo retal bipolar único 15 , com fonte de estímulo elétrico com corrente alternada de 60 ciclos e tensão variável de 0 a 25 volts. Imediatamente após uma sequência de estímulos, o pênis era exteriorizado e aplicada pressão digital e manipulação. $\mathrm{O}$ método era repetido até a obtenção do sê- 
men ou completar 25 estimulos.

$\mathrm{O}$ cletrodo retal bipolar único pode também ser abastecido por uma bateria de 12 volts 16 , adaptando-se um osciloscópio para calcular a emissto da voltagem.

Segundo alguns autores 12 , o volume ejaculado mediante eletroejaculação mantém-se relativamente constante ou sofre ligeiras quedas após períodos semanais de colheita 8 .

Dada a diversidade das indicaçōes existentes na literatura, o presente trabalho objetivou aperfeiçoar e uniformizar um aparelho eletroejaculador para ser utilizado, primordialmente, na obtenção de sêmen de cobaias, porém visando também futuras pesquisas com outras espécies de animais de laboratório que não se adaptam ao método da vagina artificial.

\section{MATERIAL E MÉTODO}

Foram utilizados 53 cobaias, Cavia porcellus, machos albinos com idade de 12 meses e peso oscilando entre $814 \mathrm{e}$ 1202 gramas, no início do experimento.

As colheitas de sêmen, com os anmaus devidamente contidos $^{1}$, foram realizadas semanalmente, durante $16 \mathrm{se}$ manas consecutivas, reunindo-se as cobaias em 9 grupos de 5 e 1 grupo de 8.

O aparelho (Figs. 1 e 2 ) produz um sinal elétrico, onda quadrada, com frequência variável e amplitude fixa. $O$ painel de controle é composto das chaves liga-desliga, seletora de modo de operação, lâmpada indicadora de funcionamento, potenciômetro de ajuste de frequência, botão para liberar a corrente, potenciômetro de ajuste do tempo de choque, potenciômetro de ajuste da corrente de saída, chaves de seleção do fundo de escala do amperímetro, amperimetro e bornes de saída.

Basicamente, o instrumento consta de 4 circuitos distintos, acoplados entre si, ou seja, fontes de alimentação (Fig. 3), circuito oscilador mais o estágio de saída, temporizador e circuito de medição (Fig. 4).

$\mathrm{O}$ aparelho foi utilizado com ajuste da fonte $\mathrm{F} 1$ para 32 v. O valor da tensão foi obtido por meio de experimentos de aferição da resistência média oferecida pelas cobaias. As medidas foram realizadas através de gerador de funções (IEC - Interestat Electronic Co. - modelo F-34), acoplado a um osciloscópio (Tektronix modelo 213), e variando entre 700 e 1200 Ohms, com médias de 1000 Ohms. Associando uma carga ativa à saída do aparelho, foi fixada a intensidade de corrente em $28 \mathrm{~mA}$, por meio do ajuste interno (R5) da fonte F1.

Para a transferência do sinal elétrico ao animal, foram utilizados 2 eletrodos: a) um na região anal, confeccionado de um fio elétrico com $14 \mathrm{~cm}$ de comprimento e $0,4 \mathrm{~cm}$ de diâmetro; cerca de $5 \mathrm{~cm}$ desse fio foi desencapado, a extremidade arredondada e na outra foi soldado outro fio (no. 18) com 2 metros de comprimento; b) outro na região lombar, composto de 2 partes: a primeira constituída de um fio no. 18 com 2 metros de comprimento, tendo em uma extremidade um prendedor do tipo jacaré; a segunda parte é um parafuso de cobre com $6 \mathrm{~cm}$, de comprimento e $3 / 8$ ' de diâ. metro, possuindo uma cabeça em forma de disco com 1,75 $\mathrm{cm}$ de diâmetro e espessura de $1 \mathrm{~mm}$, e preso ao sistema de contenção por meio de uma porca. Os eletrodos antes do uso, foram limpos com lixa no. 600 .

0 eletrodo lombar foi posicionado entre as vértebras lombares L2-L3, após tricotomia da região, e o outro introduzido a $4,5 \mathrm{~cm}$ de profundidade no reto, situado imediatamente acima do saco perineal ${ }^{3}$.

A região tricotomizada recebeu uma fina camada de pasta para eletrodo EKG sol. (Burton, Parsons e Company, Inc. Washington), com o intuito de melhorar a transmissão dos impulsos elétricos.

As regiões externas do saco perineal e o pênis desembainhado foram limpos com gaze umedecida em água destilada. O pênis foi então introduzido no coletor contendo 2 $\mathrm{ml}$ de tampão fosfato Sorensen 8 e alfa-quimotripsina (Dow Química S/A. - 22636 UP/mg), tipo II de pâncreas bovino, na proporção de $1 \mathrm{mg}$ por $\mathrm{ml}$ de tampão fosfato. $\mathrm{O}$ teste para comprovação da atividade foi executado pelo método da digestão de caseína 11 . A alfa-quimotripsina, substância que promove a liquefação do coágulo, foi utilizada devido ao fato da ejaculaçశ̃o da cobaia coagular-se em poucos segundos após a emissão. $\mathrm{O}$ cilindro coletor e seu conteúdo foram mantidos a $39{ }^{\circ} \mathrm{C}$, em banho-maria.

Ao cessar o primeiro estímulo, o pênis foi manipulado suavemente (Fig. 5) por meio de um movimento de distensão conjugado com leve pressão na glande. Na maior parte das vezes esta manobra foi suficiente para que o animal, após um retesamento do corpo acompanhado de típicos guinchos, lançasse ativamente o conteúdo seminal no interior do coletor.

Nos casos de insucesso após o primeiro estímulo, um segundo estímulo foi dado, com intervalo de 10 segundos e o processamento de manipulação era repetido. Como parâmetro, no início do experimento, foi fixado um número máximo de 5 estímulos. Nos casos em que não houve ejaculação após 3 estímulos, foi efetuada a mudança na posição do eletrodo lombar.

Durante todas as colheitas, o eletroejaculador funcionou em AC com o ajuste de tempo de liberação de choque em 4 segundos e a frequência em $100 \mathrm{~Hz}$. $\mathrm{O}$ tempo de descanso entre 2 estímulos, quando necessário, foi sempre de 10 segundos.

Por falta de dados na literatura, o sêmen foi classificado por nós visualmente no decorrer da ejaculação, como coagulado ou liquefeito, com base em uma variação de ++++ coagulado/0 liquefeito (completamente coagulado), passando por ${ }^{++}$coagulado $/^{++}$liquefeito $(50 \%$ coagulado $\mathrm{e}$ $50 \%$ liquefeito) até 0 coagulado/ ${ }^{++++}$liquefeito (completamente liquefeito). As formas gelatinosas foram classificadas como completamente coaguladas. Para facilidade de exposi- 
ção e interpretação são apresentadas na tabela 1 as proporções das formas líquidas, gelatinosas e totalmente coaguladas.

Terminada a ejaculação, a leitura do volume foi verificada diretamente no coletor graduado, construído com seringas de vidro com capacidade para $5 \mathrm{ml}$, cujos bicos foram cortados e soldados à fogo.

\section{RESULTADOS E DISCUSSĀO}

Em cobaias, o número de referências sobre a utilização do método de eletroejaculação é relativamente pequeno, embora ocorrendo grande diversificação quanto aos parâmetros utilizados e resultados obtidos. Devido a esse fato e baseados em dados fornecidos pela literatura ${ }^{16}$, construimos um equipamento que liberava corrente contínua (DC), unda quadrada, tensão variável de 0 a 9,5 volts e amperagem fixa em $5 \mathrm{~mA}$. $\mathrm{O}$ eletrodo utilizado era retal bipolar único, introduzido a $3 \mathrm{~cm}$ de profundidade. Contudo, após vários testes, os resultados mostraram ereção continuada $\mathrm{e}$ pequenas emissões de urina, de acordo com o relatado pelos autores 16 , embora afirmassem ainda que após o fato, uma série de 10 estímulos com intervalos de 10 segundos era suficiente para obter a ejaculação, o que não conseguimos repetir. Mesmo a introdução de modificações no eletrodo, variações de sua profundidade no reto e mudanças na duração do tempo de estímulo, não surtiram o efeito desejado.

Assim sendo, outras informações $4,6,7,15$ foram levadas em conta. Devido ao fato dos dados serem diversificados, os testes foram efetuados por meio de um gerador de funções, acoplado a um osciloscópio e os resultados positivos foram anotados, observando-se que a corrente alternada com onda quadrada era a que produzia resultados mais consistentes, mas não com a frequência de $60 \mathrm{~Hz} 15$. Verificouse ainda que a aplicação da frequência de $1000 \mathrm{~Hz}^{3}$ produzia ejaculações mais frequentes e evitava desconforto aos animais, enquanto $60 \mathrm{~Hz}$ provocava-lhes movimentos bruscos. A utilização do eletrodo com polos separados aplicados nas regið̄es ano-lombar 4,7 associada à corrente alternada, onda quadrada, frequência de $1000 \mathrm{~Hz}$ e estímulos com duração de 4 segundos e intervalos de descanso de 10 segundos, propiciaram a obtenção de um número apreciável de ejaculações, contudo não muito regulares, pois o número de estímulos variou grandemente, prejudicando o objetivo de obter repetições.

Um novo dado 7 , referente à aplicação do eletrodo lombar na posição L2-L3, melhorou as condições conquanto permanecessem a inconstância na obtenção do sêmen e a não padronização do número máximo de estímulos. Partimos então para o princípio de que a corrente, e não a tensão, é que determina a intensidade de um estímulo elétrico. Assim, várias medidas foram executadas nas cobaias a fim de obter os valores da resistência interna oferecida ao estímulo elétrico. Utilizando o osciloscópio verificamos um va- lor médio de 1000 Ohms, com variação de 700 a 1200 . Associamos então uma carga ativa à saída do aparelho e fixamos a intensidade da corrente em $28 \mathrm{~mA}$, por meio de ajuste interno da fonte $\mathrm{F} 1$ para 32 volts. Deste modo, as colheitas passaram a ser frequentes, mas o número de estímulos continuava muito variável e na tentativa de padronizá-lo, ocorria que alguns animais não haviam ejaculado ao atingirem o número máximo e a maior parte do material colhido era sob forma totalmente coagulada.

Assim, uma nova técnica foi introduzida, combinando o estímulo elétrico com a manipulação do pênis 15 . A partir de então, o processo passou a ter repetição e colheitas consecutivas foram obtidas ativamente sob forma não coagulada. O número de estímulos para alguns animais continuou variável, contudo, com até 5 estímulos no máximo o material era colhido, por vezes passivamente. Este fato repetiu-se frequentemente nos mesmos animais, em colheitas efetuadas semanalmente, denotando características individuais, não obstante as ejaculações ocorrerem em grande número, após a aplicação de no máximo 2 estímulos, possibilitando assim a fixação de um padrão.

O nosso aparelho não possui amplificador 7 , mas um sistema oscilador. $O$ processo de manipulação após o estímulo, por ser eficiente na maior parte das colheitas, evita a utilização de sistemas mecânicos ou eletro-eletrônicos mais complexos para a regularização do tempo de descanso, podendo isso ser feito por meio de um cronômetro.

É evidente que os dados sobre os níveis que controlam a ereção e a ejaculação não podem ser usados para uma localização precisa dos centros espinais na cobaia. Quando estímulos externos são aplicados, a parte do sistema nervoso que efetivamente os recebe é incerta, visto que os nervos eferentes que emergem da espinha ou os centros da corda espinal podem ser estimulados.

Os eletrodos retais bipolares únicos 15,16 não mostraram eficiência para a obtenção de ejaculações, provavelmen. te porque o centro da ejaculação ou os nervos emergentes da corda espinal não foram atingidos pelos estímulos elétri$\cos$. A ereção obtida é explicada devido a localização de seu centro encontrar-se ao nivel das vértebras sacras, enquanto que o centro da ejaculação situado mais acima, provavel. mente não seja atingido por um único eletrodo por via retal.

A média obtida do volume ejaculado de 553 amostras foi de $0,97 \mathrm{ml}$, aproximando-se dos valores citados na literatura de $0,5 \mathrm{ml}^{6}, 0,3$ a $0,6 \mathrm{ml}^{12}$ e 0,5 a $1,5 \mathrm{ml}^{7}$, embora, em 38 colheitas, fossem obtidos volumes variando de 2 a $3 \mathrm{ml}$. Neste aspecto, também não se verificaram ligeiras quedas de volume ejaculado após periodos semanais de colheita, que seriam características da cobaia 8

Verifica-se na tabela 1 que com um estímulo e subsequente manipulação do pênis foram obtidas 203 colheitas $(34,35 \%)$ dentre as 591 efetuadas e que após 2 estímulos conseguiram-se $182(30,80 \%)$ amostras. Assim, 385 $(65,15 \%)$ amostras foram obtidas com somente 2 estímulos. Não houve caso em que não se tivesse conseguido o material 
espermático. Ainda na nossa tabela, pode-se verificar que a característica física do ejaculado foi predominantemente sob a forma gelatinosa em 501 (84,77\%) das amostras. Devido ao fato do material espermático ser geralmente emitido sob a forma coagulada ou em parte coagulado 7,15 , as formas gelatinosas obtidas mostram que quando o animal eja. cula ativamente não hå tempo suficiente para que a vesicu- lase promova a coagulaç⿸̃ do sêmen antes de ser expelido. A importancia da obtençáo do ejaculado sob essa forma deve-se ao fato de que a amostra ao ser colhida na solução tampão adicionada de alfa-quimotripsina permite à enzima agir sobre os sítios da prote ína ainda não ocupados pela vesiculase, propiciando liquefação mais eficiente.

TABELA 1 - Sêmen de cobaia, Cavia porcellus, obtido por eletroejaculação. Distribuição dos estímulos elétricos aplicados e das características físicas das ejaculaçōes. São Paulo, 1978.

\begin{tabular}{|c|c|c|c|c|c|c|c|c|c|c|c|c|c|c|}
\hline \multirow{3}{*}{$\begin{array}{l}\text { Gru- } \\
\text { pos }\end{array}$} & \multirow{3}{*}{$\begin{array}{l}\text { No. de } \\
\text { Colhei- } \\
\text { tas }\end{array}$} & & \multirow{2}{*}{\multicolumn{4}{|c|}{$\begin{array}{l}\text { Colheitas por Número } \\
\text { de Estímulos Elétricos }\end{array}$}} & \multicolumn{8}{|c|}{ Características Físicas das Ejaculaçסes } \\
\hline & & & & & & & \multicolumn{5}{|c|}{ Critério I } & \multicolumn{3}{|c|}{ Critério II } \\
\hline & & 1 & 2 & 3 & 4 & 5 & ${ }^{++t+} / 0$ & $+++1^{+}$ & $++1^{++}$ & $+1^{+++}$ & $0 /^{++++}$ & $\begin{array}{l}\text { Completa- } \\
\text { mente } \\
\text { coagulado }\end{array}$ & $\begin{array}{r}\text { Gelati- } \\
\text { noso }\end{array}$ & $\begin{array}{l}\text { Lique- } \\
\text { feito }\end{array}$ \\
\hline 1 & 51 & 2 & 12 & 7 & 14 & 16 & 28 & 8 & 1 & 3 & 11 & 6 & 31 & 14 \\
\hline 2 & 60 & 20 & 28 & 5 & 4 & 3 & 29 & 24 & 4 & 3 & 0 & 4 & 53 & 3 \\
\hline 3 & 60 & 25 & 24 & 7 & 3 & 1 & 38 & 5 & 3 & 4 & 10 & 0 & 46 & 14 \\
\hline 4 & 60 & 28 & 16 & 8 & 3 & 5 & 47 & 11 & 1 & 1 & 0 & 2 & 57 & 1 \\
\hline 5 & 60 & 24 & 11 & 5 & 6 & 14 & 38 & 19 & 1 & 0 & 2 & 5 & 53 & 2 \\
\hline 6 & 60 & 16 & 9 & 17 & 13 & 5 & 39 & 7 & 2 & 0 & 12 & 6 & 42 & 12 \\
\hline 7 & 60 & 21 & 18 & 7 & 8 & 6 & 49 & 8 & 1 & 1 & 1 & 5 & 53 & 2 \\
\hline 8 & 60 & 22 & 16 & 8 & 6 & 8 & 50 & 4 & 5 & 1 & 0 & 4 & 55 & 1 \\
\hline 9 & 60 & 19 & 21 & 10 & 3 & 7 & 46 & 10 & 2 & 2 & 0 & 3 & 55 & 2 \\
\hline 10 & 60 & 26 & 27 & 5 & 2 & 0 & 29 & 23 & 5 & 2 & 1 & 1 & 56 & 3 \\
\hline 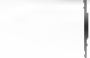 & 591 & 203 & 182 & 79 & 62 & 65 & 393 & 119 & 25 & 17 & 37 & 36 & 501 & 54 \\
\hline$\%$ & 100,0 & 34,35 & 30,80 & 13,37 & 10,49 & 10,99 & 66,50 & 20,13 & 4,23 & 2,88 & 6,26 & 6,09 & 84,77 & 9,14 \\
\hline
\end{tabular}

$++++/ 0=$ completamente coagulado

${ }^{+++} 1^{+}=$proporcionalmente mais coagulado do que liquefeito

${ }^{++} 1^{++}=50 \%$ coagulado e $50 \%$ liquefeito

${ }^{+} /^{++}=$proporcionalmente mais liquefeito do que coagulado

$0 /^{++++}=$completamente liquefeito

A eficiência enzimática da alfa-quimotripsina foi observada quando o material espermático era emitido sob a forma gelatinosa. Mesmo assim, dentro do período preconizado de uma hora, não houve liquefação completa do material, observando-se em algumas amostras, espermatozóides presos em malhas. Nos casos em que o material foi emitido sob a forma de coágulo, sua ação era parcial, observando-se restos de coágulos no fundo do cilindro coletor ao término de uma hora.

Experimentos prévios foram executados para a observação da ação da alfa-quimotripsina em quantidades de até $5 \mathrm{mg}$ por ml de tampão, durante uma hora. A enzima colhi- 
da desses tubos e levada a promover ação hidrolítica sobre um substrato mais simples, case ina 11 , mostrou-se ativa, tendo o mesmo ocorrido quando experimentos prévios foram feitos com quantidades de $1 \mathrm{mg}$ por $\mathrm{ml}$.

Eletroejaculações bisemanais ou mesmo semanais mostram aumento progressivo de amostras liquefeitas 6,16 . Este fato, contudo, não foi observado durante nosso experimento. Amostras liquefeitas foram obtidas de alguns animais que desde a primeira ejaculação mostraram emissōes líquidas; outros animais apresentaram ejaculaçðes liquefeitas combinadas com porçðes gelatinosas ou totalmente coaguladas e, esporadicamente, em determinada colheita, ejacularam amostras liquefeitas, sem continuidade nas colheitas seguintes.

O aspecto característico de espermatozóides de cobaias, acumulados com as cabeças empilhadas verticalmente (Fig. 6) foi comprovado no presente experimento, sendo camumente encontrado nas ejaculaçōes dos animais trabalhados.

\section{CONCLUSÕES}

Dentro da metodologia utilizada no presente trabalho, visando aperfeiçoamento e uniformização de aparelho eletroejaculador para cobaias, foi-nos permitido concluir que: 1 . o eletroejaculador e o método de colheita mostraram elevada eficiência na obtenção de 591 amostras de sêmen, sem ocorrência de qualquer insucesso; 2. das 591 amostras colhidas, 203 foram obtidas com apenas um estímulo elétrico, sendo que 182 necessitaram 2 estímulos, obtendo-se desta forma um porcentual de $65,15 \% ; 3$. o uso do limite máximo pré fixado, 5 estímulos, foi necessário para a obtenção de somente $10,99 \%$ das amostras; 4 . o processo de disposição dos eletrodos nas regiões ano-lombar (L2-L3), mostrou-se adequado e altamente eficiente; 5. a obtenção de ejaculações sob a forma gelatinosa emitidas ativamente pelo animal atingiu 501 ou seja $84,77 \%$, enquanto que os totalmente coagulados representaram 6,09\% (36 amostras); 6. não foi observada crescente obtenção de amostras liquefeitas, nas colheitas efetuadas semanalmente; 7. o emprego de alfa-quimotripsina para liquefação do coágulo foi satisfa tório quando as amostras foram obtidas sob a forma gelatinosa, atuando parcialmente sobre as formas totalmente coaguladas; 8 . melhores resultados foram obtidos com est ímulos elétricos com duração de 4 segundos e intervalos de 10 segundos, seguidos de manipulação suave do pênis por meio de movimento de distensão conjugado com leve pressão na glande.

SANTOS, O.R.; BARNABE, R.C.; BARNABE, V.H.; SANTOS, M.V.H.R.; SGAMBATTI JUNIOR. A. Improvements in an apparatus designed for electrical cjaculation in the guinea-pig (Cavia porcellus). Rev.Fac.Med.vet.Zootec.Univ.S.Paulo, 19(1) $75-85,1982$.

SUMMARY: The procedure here described appears to be a precise, repeatable and non-traumatic method of eletrocjaculation, which might be of utility in studics such as those performed to determinc the effects of both radiation and/or drugs on sperm production in the guinea-pig (Cavia porcellus). Essentially, the electro-ejaculator device consists of four distinct and coupled circuites: a power supply, an oscillator circuit with a driver, a timer and a meter circuit, connected toa a $110 \mathrm{~V}, 60 \mathrm{~Hz}$ source. A guinea-pig analogue output (parallel RC circuit) was associated to the apparatus yielding a fixed current of $28 \mathrm{~mA}$. Two electrodes were utilized in order to transfer the electric signal to the animal: one anal and one lumbar (placed between vertebra L1-L3). The electric pulse, in a maximum number of five, were given at 10 seconds intervals. During semen collections, that were performed weekly, the apparatus worked in a AC current (square wave) with a 4 seconds time adjustment for shocks that were delivered in a frequency of $1000 \mathrm{~Hz}$. Electrode jelly was applied to the skin to ensure a perfect electrical contact with lumbar electrode. A total of 591 ejaculations were obtained from 53 animals, during 16 weeks; the semen was collected in $2 \mathrm{ml}$ Sorensen phosphate buffer containing $2 \mathrm{mg}$ alfa-chymotrypsin.

UNITERMS: Eletroejaculator*; Guinea-pig, semen* 


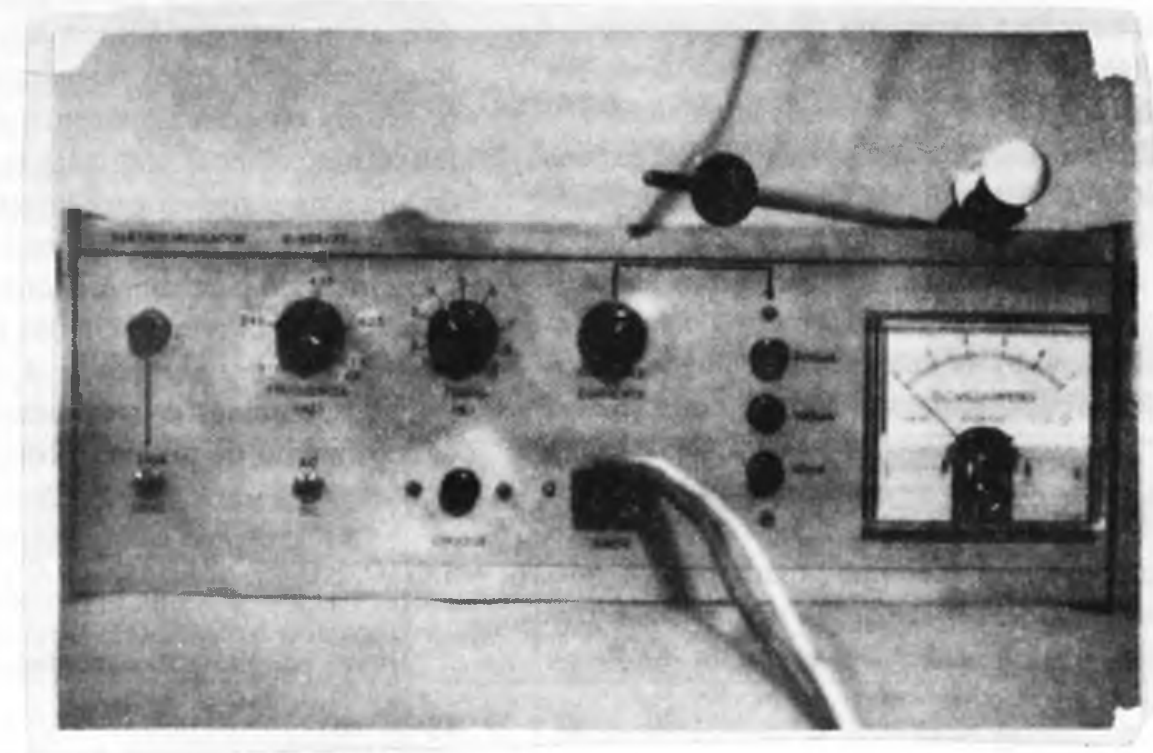

Fig. 1 - Painel do eletroejaculador. Eletrodos anal e lombar.

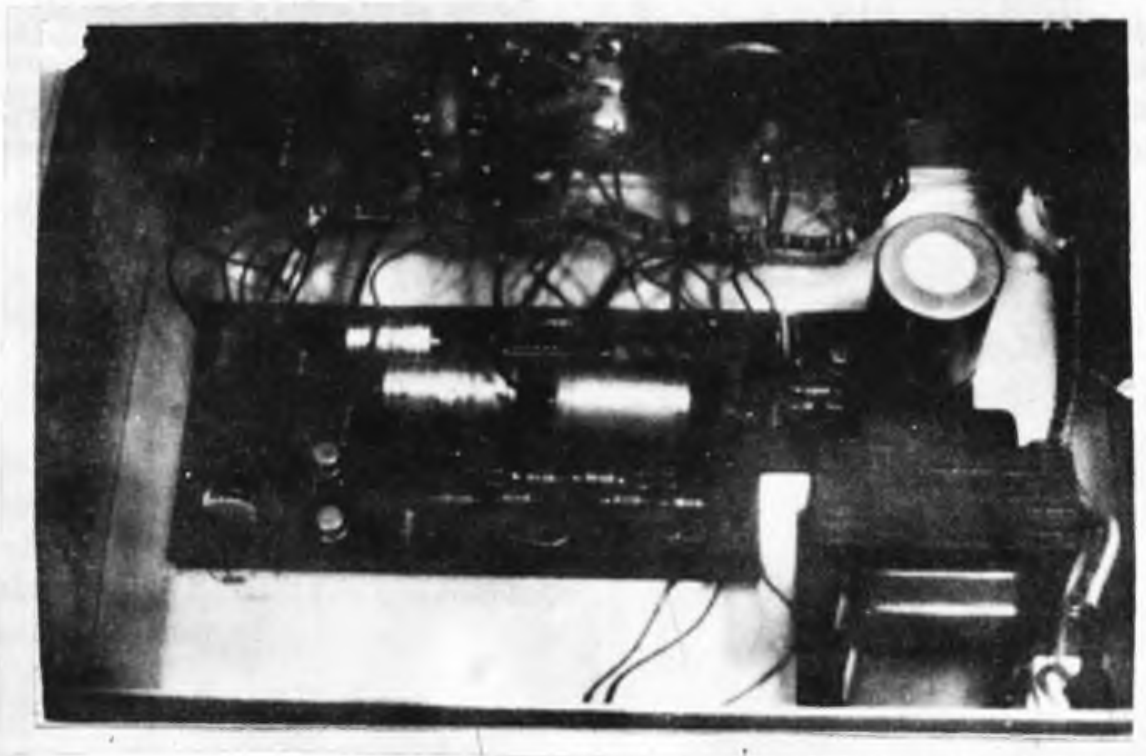

Fig. 2 - Parte interna do eletroejaculador. 


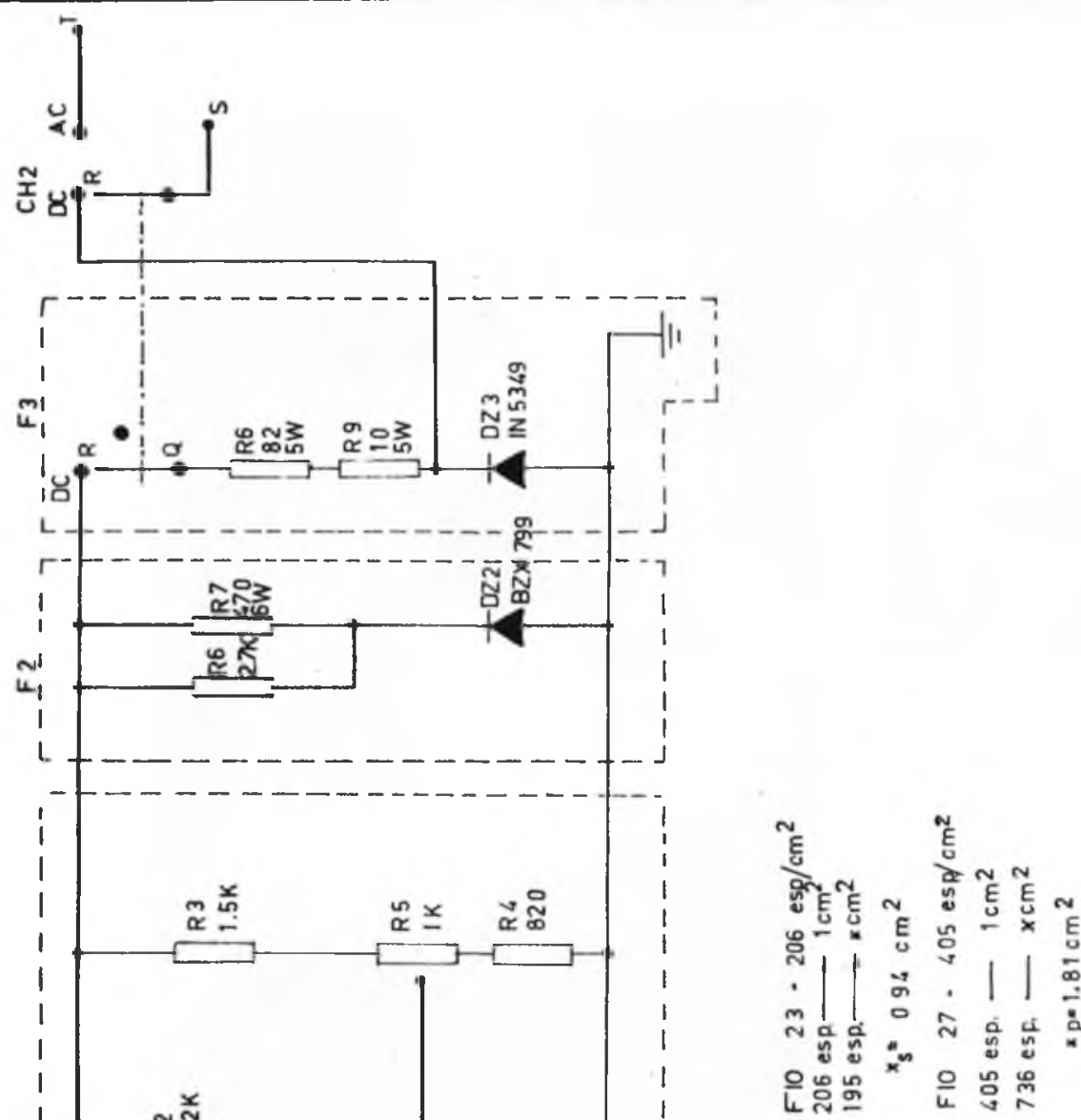

$\sum_{\underline{\underline{\alpha}}}^{\underline{N}}$

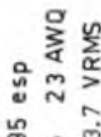

紧, 离

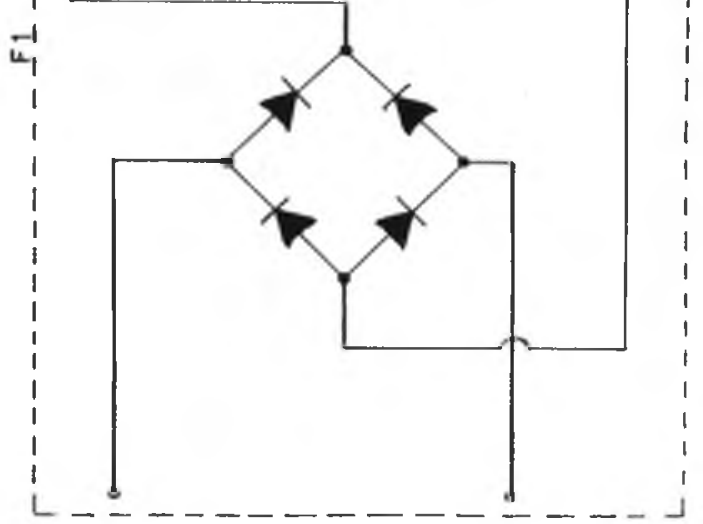




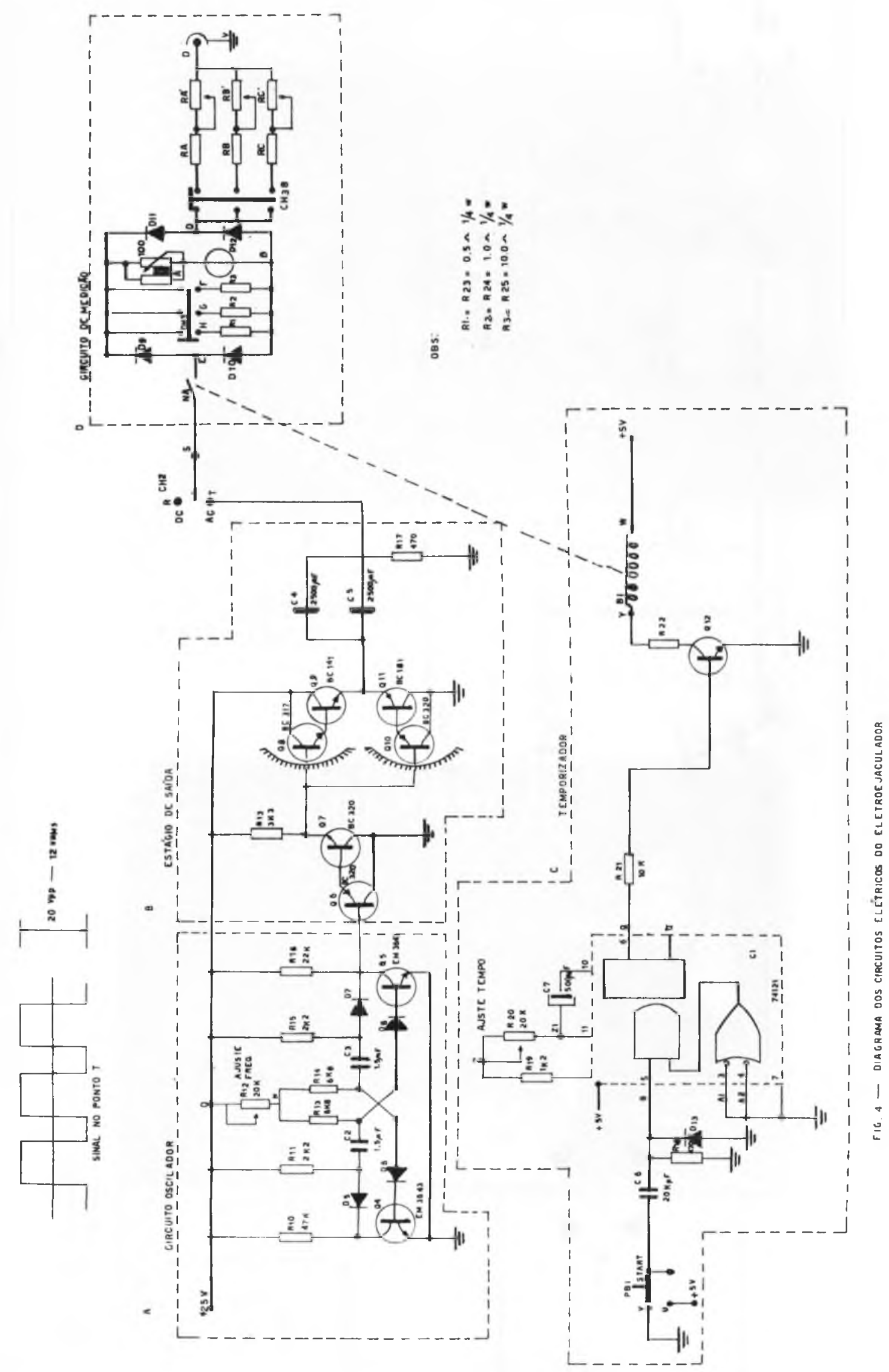




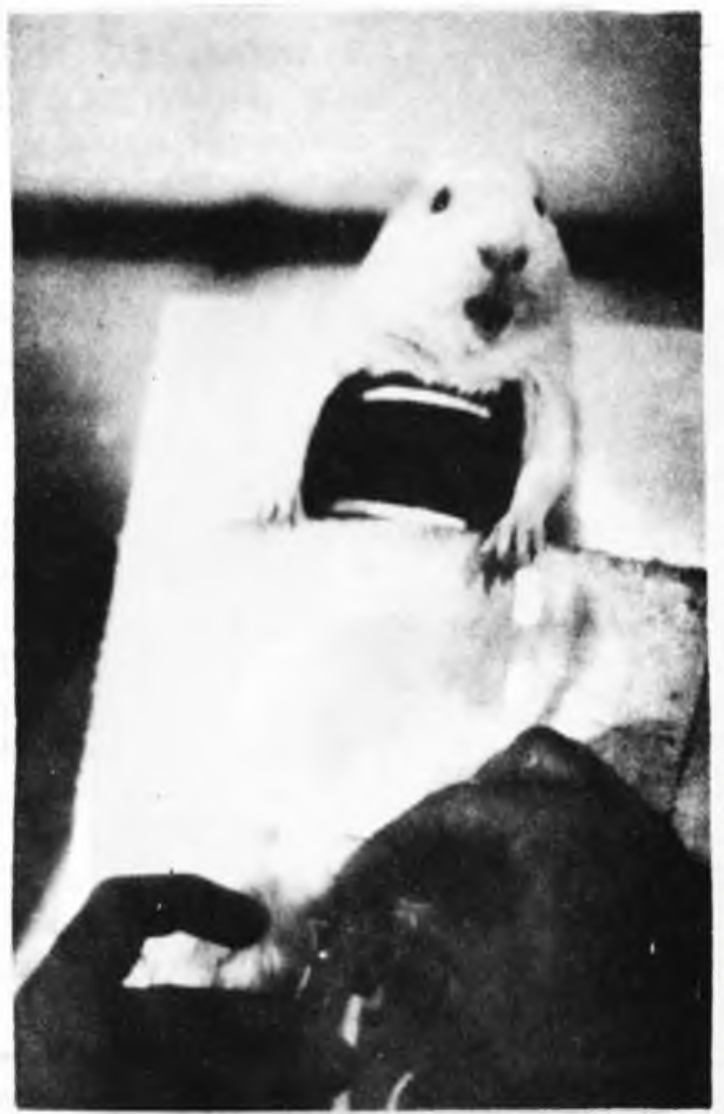

Fig. 5 - Detalhes da ejaculação: animal contido; disposição do eletrodo anal e ato da colheita. 
84 SANTOS, O.R.; BARNABE, R.C.; BARNABE, V.H.; SANTOS, M.V.H.R.; SGAMBATTI JUNIOR, A.

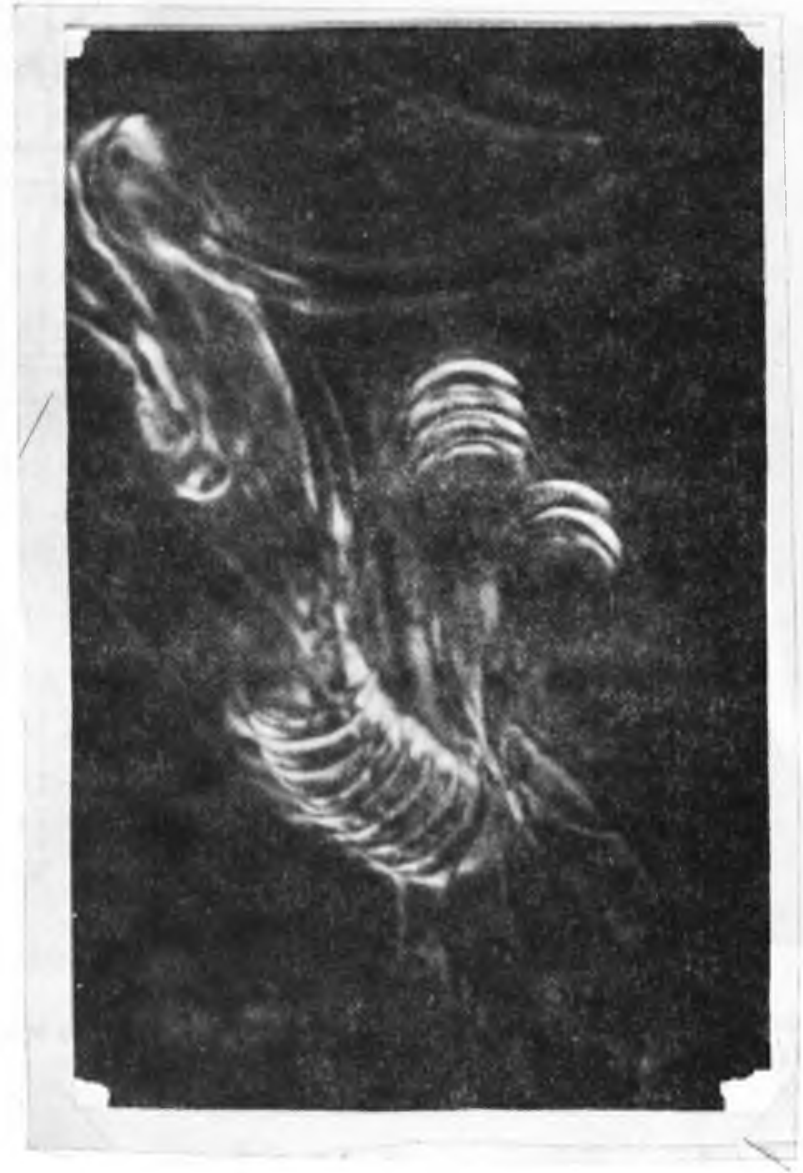

Fig. 6 - Espermatozóides normais. Empilhamento. Contraste de fase. 5400X. 


\section{REFERÊNCIAS BIBLIOGRÁFICAS}

1 - BARNABE, R.C.; SANTOS, O.R.; BARNABE, V.H.; SANTOS, M.V.H.R.; VIANA, W.G. Dispositivo de contenção para eletroejaculação em cobaias. Comun.cient.Fac.Med.vet. Zootec.Univ.S.Paulo, 4(1):37-8, 1980.

2- BATELLI, F. Une méthode pour obtenir l'emission complète du liquid des visicules séminales chez le cobaye. C.R.Soc.Phys.Hist nat.Genéve, 39: 73.4, 1922 .

3- COOPER, G. \& SCHILLER, A.L. Anatomy of the guinea pig. Cambridge, Harvard University, 1975.

4- DALZIEL, C.F. \& PHILLIPS, C.L. Electric ejaculation. Determination of optimum electric shock to produce ejaculation in chinchillas and guinea pigs. Amer.J.vet.Res., 9:225-32, 1948.

5- DURFE, T.; LERNER, M.W.; KAPLAN, N. The artificial production of seminal ejaculation. Anat. Rec., 76:65-8, 1940.

6- FREUND, M. Collection and liquefaction of guinea pig semen. Proc.Soc.exp.Biol., 98:538-40, 1958.

7- FREUND, M. Interrelationships among the characteristics of guinea-pig semen collected by electroejaculation. J.Reprod.Fertil., 19:393-403, 1969.

8- FREUNI). M \& BORRELLI, F.J. The effects of Xirradiatıom on male fertility in the guinea pig. Effect of 75,150 and 300 roentgens of wholebody $X$-irradiation on semen production. Radiat. Kes., 22:404-13, 1964.

9- GOMORI, G. Preparation of buffers for use in enzyme studies. In: COLOWICK, S.P. \& KAPLAN, N.O., eds. Methods in enzymology. New York, Academic, 1955. vol.II, cap.16. p 143.
10- GUNN, R.M.C. Fertility in sheep, artificial production of seminal ejaculation and the characters of the spermatozoa contained therein. Australia, Council for Scientific and Industrial Research, 1936. (Bull. 94) apud DALZIEL, C.F. \& PHILLIPS, C.L. Electric ejaculation. Determination of optimum electric shock to produce ejaculation in chinchillas and guinea pigs. Amer.J. vet.Res., 9:225-32, 1948.

11- KUNITZ, M. Crystalline soybean trypsin inhibitor. II. General properties. J.gen Physiol., 30:291-310, 1947.

12- LAURENCE, K.A. \& CARPUK, O. The counting and sizing of guinea pig spermatozoa. Fertil.and Steril., 14:451-5, 1963.

13- MOORE, C.R. \& GALLACHER, T.F. Seminal vesicle and prostate function as a testis-hormone indicator: the electric ejaculation test. Amer.J. Anat., 45:39-69, 1930.

14 - SAYLES, E.D. Postnatal development of reproductive system in male guinea pigs and its relation to testis hormone secretion. Physiol.Zool., 12:256. 1939.

15- SCOTT, J.V. \& DZIUK, P.J. Evaluation of the electroejaculation technique and the spermatozoa thus obtained from rats, mice and guinea pigs. Anat Rec., 133:655-65, 1959.

16- SUMAR, J.; NOVOA, C.; FRANCO, B. Contribución al conocimiento de la vida reproductiva de los roedores peruanos. Bol.Inst.vet.Invest.trop. Altura, Lima, 3:255-9, 1968.

Recebido para publicação em: 25-08-81. Aprovado para publicação em: 06-04-82. 